\title{
On the Alternate Use and Complementation of Grammar: Translation Method and Communicative Language Teaching Method
}

\section{Yin Hua}

School of Foreign Language, Yangtze University, Jingzhou, Hubei, P. R. China.

Type of Work: Peer-Reviewed

DOl: http://dx.doi.org/10.21013/jems.v16.n1.p3

\section{How to cite this paper:}

Hua, Y. (2020). On the Alternate Use and Complementation of Grammar: Translation Method and Communicative Language Teaching Method. IRA International Journal of Education and Multidisciplinary Studies (ISSN 2455-2526), 16(1), 10-14. doi: http://dx.doi.org/10.21013/jems.v16.n1.p3

(C) Institute of Research Advances.

This work is licensed under a Creative Commons Attribution-Non Commercial 4.0 International License subject to a proper citation to the publication source of the work.

Disclaimer: The scholarly papers as reviewed and published by the Institute of Research Advances (IRA) are the views and opinions of their respective authors and are not the views or opinions of the IRA. The IRA disclaims of any harm or loss caused due to the published content to any party.

Institute of Research Advances is an institutional publisher member of Publishers International Linking Association Inc. (PILA-CrossRef), USA. The institute is an institutional signatory to the Budapest Open Access Initiative, Hungary advocating the open-access of scientific and scholarly knowledge. The Institute is a registered content provider under Open Access Initiative Protocol for Metadata Harvesting (OAI-PMH).

The journal is indexed \& included in WorldCat Discovery Service (USA), CrossRef Metadata Search (USA), WorldCat (USA), OCLC (USA), Open J-Gate (India), EZB (Germany) Scilit (Switzerland), Airiti (China), Bielefeld Academic Search Engine (BASE) of Bielefeld University, Germany, PKP Index of Simon Fraser University, Canada. 


\begin{abstract}
Grammar-translation method and communicative language teaching method are the two most important methods of foreign language teaching at home and abroad, each of which holds its own advantages and disadvantages, and complements each other. The organic combination and alternate use of the grammar-translation method and communicative teaching method will help to improve the efficiency of foreign language teaching.
\end{abstract}

Key Words: Grammar-translation method, Communicative Language Teaching Method, Alternate use and complementation.

Since Peking Tungwen College (1862), English teaching developed in China for one and a half centuries. Before the 1980s, the grammar-translation method was the main method of English teaching in China. With the deepening of reform and opening-up, the rapid development of economy, culture and science and technology in China urgently needs practical foreign language talents. As a result, other foreign English teaching theories and methods are constantly introduced, among which the most popular one is the communicative teaching method. However, the communicative teaching method has been pushed for more than 20 years with a slight effect, and it seemed to be reduced in a dilemma. It is a topic that foreign language educators should explore how to use all kinds of teaching methods synthetically on the basis of the teaching situations and make full use of their strengths and avoid their weaknesses. On the basis of discussing the emergence, development, application, advantages, and disadvantages of the grammar-translation method and communicative teaching method, this paper points out the necessity and possibility of alternating and complementing the two teaching methods in specific teaching situations.

\title{
1. The Application of the Grammar-Translation Method and Communicative Teaching Method in China
}

Under certain historical conditions, any English teaching method holds the theoretical and practical basis for its emergence, existence, and development, which is closely related to the social development at that time, individuals' purpose of learning foreign languages, popular philosophical ideas, and related theories. The grammar-translation method has the longest history and the most far-reaching influence on foreign language teaching. Up to now, as a foreign language teaching method, it has been still in the ascendant, widely used and quite successful (Zhu,1994). In the 18th century, scholars, studying and classifying on parts of speech, laid an important foundation for grammar-translation method, and gradually formed a relatively complete grammatical system. The establishment of the Greek-Latin grammatical system initially completed the outline and basic framework of the grammatical translation method. The grammar-translation method finally came into being in the early 19th century. At that time, the main purpose of learning a foreign language was to have an ability to read Greek and Latin books as well as communicate with them. From the 1940s to the $1940 \mathrm{~s}$, the grammar-translation method has been dominant in foreign language teaching in Europe. In China, From the middle of the 19th century, in which English was introduced into missionary schools by missionaries to the end of the Qing Dynasty in 1911, schools in China universally adopted the "grammar-translation teaching method" which prevailed in Europe during the same period" (Gu, 2002). After the Opium War, especially the Second Opium War, there was an urgent need for English and French language talents. In order to meet the needs of the situation, the Qing government set up foreign language schools, such as Peking 
Tungwen College, Shanghai Guangzhou Dialect College, and Guangzhou Tongwen college. At that time, the translation advocated by Peking Tungwen College only existed as a grammar-translation method, one of the foreign language teaching schools (Mu Lei, 1999:7)."By the mid-20th century, the grammar-translation method had accumulated a lot of experience. Through the efforts and practice of educators of all times, it overcomes some weaknesses of the classical translation method and developed into a modern translation method, which was called 'translation-reading method'" (Liu Runqing; 1999: 147). In the 20th century, due to the qualitative success in the research of language teaching theory and the combination with the research results of other disciplines, various distinctive teaching methods have been produced and introduced into China, such as audio-lingual method, direct method, situational method, The Functional-Notional Approach, silence method, etc. However, the grammar-translation method has not been replaced by them and has kept pace with other teaching methods.

"Communicative approach teaching refers to creating some information omissions or spaces in classroom teaching and allowing students to provide the necessary information to fill these information spaces. Filling this information space requires two or two groups of people to interact in one language communicative activity, such as questions and answers, and make a bridge to fill the information space in the language learner's learning" (Johnson; 1982: 201). The communicative approach emerged in the early 1970s with language function and a teaching method that focuses on developing communicative competence. "Because the interdependence between European countries was increasing," "and it raised the importance of learning the language from each other between European Community countries, the idea of communicative approach teaching was quickly brought to the attention of the European Community. This method was called communication at that time. Law or Communicative Language Teaching" (Richards \& Rodgers; 1999: 64-65). The emergence of communicative law is also closely related to the development of linguistic theories. Chomsky's transformed-generative grammar theory distinguishes between language ability and language use. Since then, Hymes proposed the concept of “communicative ability" which is opposite to Qiao's "language ability."The idea of communicative language teaching is the meeting point of new ideas and new methods of foreign language teaching in the early 1980s. Communicative approach teaching is still widely used in many countries and regions around the world. In the 1980s, the communicative approach was introduced to China, and vigorously promoted in the early 1990s. Teachers have gained some experience and achievements from the emphasis on language knowledge to language use, but there are still some problems, such as conceptual misunderstanding, lack of profound analysis and comprehensive understanding, blindly using foreign teaching models, etc., which lead to the communicative language teaching method shows various incompatibility in English teaching in China.

\section{The advantages and disadvantages of the Grammar-Translation Method and Communicative} Approach teaching method

Although there are deficiencies in grammar-translation, for a century and a half, English teaching in China also using it. There are many advantages. In addition, our teachers have long used grammar-translation to teach students, and they all get used to this teaching method. However, bringing in the communicative approach has challenged grammar-translation. In response to this complicated situation, it is not only necessary but also very practical to make a new discussion on grammar translation and communicative approach teaching methods. Recognizing the advantages and 
disadvantages of these two main teaching methods in China play a guiding role in foreign language teaching.

The teaching of grammar-translation focuses on the combination of pronunciation, grammar and vocabulary teaching. It focuses on cultivating reading and translation competence, taking into account listening and speaking training, and adopts grammar as a starting point, emphasizing the central position of grammar in teaching, and promoting mother tongue and foreign language learning. The grammar-translation teaching method use translation as both a teaching method and a teaching purpose. The advantages of grammar-translation in foreign language teaching are mainly reflected in: grammar teaching is dominant, which help learners to understand and translate foreign languages, and also helps to "exercise wisdom" and cultivate learners' logical thinking ability; learners can grasp the grammar rules systemly, and lay a solid language foundation for further reading and translating ability. Grammar-translation also has its limitations: it exaggerates the role of grammar and mother tongue in foreign language learning; excessive emphasis on written expression, neglecting oral teaching; over-emphasis on the transfer of language knowledge, neglecting the cultivation of language skills, do harm to the development of foreign language for students the ability to communicate; and the teaching method is single, the teaching process is mechanical, the language environment and practical significance are ignored.

The communicative approach teaching method is characterized by combining the structure and function of language for communicative teaching; emphasizing learner-centered rather than teacher-centered; focusing on the authenticity of the content of the textbook; requiring learning means and its ultimate purpose ( master the ability to use language for communication). The advantages of communicative approach teaching method are: pay attention to the communicative effect of language, authentically language materials, provide students with more realistic communication scenarios, stimulate learners' interest in learning; emphasize learners' initiative and interaction, pay attention to training learners to use the ability of language to communicate and the awareness of learning. However, cause the communicative approach teaching method has high requirements on teaching conditions (teaching facilities, teaching environment, teaching materials, etc.), there are limitations in specific teaching practices: the textbooks written mainly on functions are not systematic, and it is difficult to judge their learning outcome for effective evaluation and testing of the results, and the classroom teaching communication often comes at the expense of the accuracy of the language.

\section{The necessity of the alternation and complementation of the Grammar-Translation Method and Communicative Teaching Method}

The advantages of the Grammar-translation method and Communicative Teaching method show that they are not totally opposed. They are complementary to each other. Grammar Translation method emphasizes linguistic knowledge, rules, and frameworks, while the communicative method emphasizes linguistic knowledge. Emphasis is placed on the practical use of language, so using the two methods alternately can achieve complementary advantages. Grammar Translation method in Foreign Language Teaching in China is regarded as an important and effective method. In the past, a large number of foreign language learners who have a solid foundation in language and writing, a strong understanding ability, a higher reading Reading proficiency, knowledgeable, deep understanding of the target language were cultivated using this way in China. But in the process of Communicative Approach 
teaching, the content of teaching activities is rich, and its implementation is for learners. The fresh feeling can not only activate the classroom atmosphere but also stimulate their learning interest and can cultivate learners' practical ability to use the language. Moreover, the Communicative teaching method owns the effect that traditional and considerable mechanical exercises can not achieve. Therefore, the combination of the two teaching methods will be conducive to improving teaching efficiency.

The actual situation of our country shows that the combination of the Grammar Translation Method and Communicative Teaching method is also necessary. The Grammar Translation Method is "one kind" Minimum feasible teaching method (Zhou Liuxi; 1995:153). In classroom teaching, teachers who use the Grammar-Translation Method don't need so fluent Spoken English. Generally, teachers just have to interpret and explain the exact meaning of the language you have learned in your mother tongue according to the text, word by word, sentence by sentence. Teachers only need to master the basic knowledge of foreign languages, and they don't need any teaching aids and equipment. In this kind of teaching method, the classroom teaching process is better controlled, It's also easier to choose the test method for students. For many years, due to historical reasons, The overall foreign language proficiency of the people in our country is not high-standard and the quality of teachers is poor. Especially in the vast rural and economically underdeveloped areas, large class teaching is implemented. In view of this situation, the Grammar Translation Method is in line with our country's "emergency" teaching method of national conditions to a certain extent. But after the reform and opening up, With the increasingly strengthening of international exchanges, our country is in urgent need of a large number of oral English speakers, which is obvious. However, the simple Grammar Translation Method can not accomplish this teaching task. The combination of the Communicative teaching method and the Grammar-translation method can make up for the lack of the sufficiency because communicative teaching method focuses on communication in real life and pays attention to guiding learners to engage in authentic verbal communication activities. Besides, this method learns from tightly connect the actual needs of the learners with their learning activity through the learning practice not only in the classroom but also out of the classroom to develop learners' oral communicative competence.

\section{References:}

[1]. Johnson, K. Communicative Syllabus Design and Methodology[M].Oxford: Pergamon, 1982.

[2]. Richards, J.\& Rodgers, T. Approaches and Methods in Language Teaching[M]. Cambridge: Cambridge University Press, 1986.

[3]. GU Wei-xing.An Analysis of the Grammar-Translation Approach in the Late Qing Dynasty [J] Journal of Soochow University, 2002, (2): 87-90.

[4]. Liu Runqing.On College English Teaching [M].Beijing: Foreign Language Teaching and Research Press, 1999.

[5]. Murray, Research on Translation Teaching in China [M].Shanghai: Shanghai Foreign Language Educatio n Press, 1999.

[6]. Wang Mingyu.Foreign Language Teaching Theory: Teaching Research, Teaching, and Teaching Skills [M].Hefei: Anhui People‘s Publishing House, 1999.

[7]. Zhou Liuxi.Chinese Middle School Encyclopedia of English Teaching [m].Shenyang: Northeast Univers ity Press, 1995.

[8]. Zhu Chun.Foreign Language Education Psychology [M].Shanghai: Shanghai Foreign Language Educati on Press, 1994. 